\title{
Comparison of expression patterns for placenta growth factor, vascular endothelial growth factor (VEGF), VEGF-B and VEGF-C in the human placenta throughout gestation
}

\author{
D E Clark, S K Smith, D Licence, A L Evans and \\ D S Charnock-Jones
}

Reproductive Molecular Research Group, Department of Obstetrics and Gynaecology, University of Cambridge, Rosie Hospital, Cambridge, CB2 2SW, UK

(Requests for offprints should be addressed to D S Charnock-Jones)

\begin{abstract}
Angiogenesis and vascular transformation are important processes in the normal development of the placenta. Vascular endothelial growth factor (VEGF) is a potent angiogenic growth factor and is thought to be important for placental development. Recently several new members of this family have been described. In this study we used in situ hybridisation to localise which cells in the placenta expressed mRNA for VEGF, placenta growth factor (PlGF), VEGF-B and VEGF-C. We were unable to find any message for either VEGF-B or VEGF-C in the placenta, suggesting that only low levels are produced which this
\end{abstract}

method was unable to detect. The mRNA encoding VEGF was found to be produced by cells within the villous mesenchyme, decidual macrophages and decidual glands but, in contrast to our previous findings, not by trophoblast. The mRNA encoding PlGF was produced in large amounts by villous cytotrophoblast, syncytiotrophoblast and extravillous trophoblast. The mRNAs encoding VEGF and PlGF were thus not co-localised and it appears that there is unlikely to be any significant production of VEGF/PlGF heterodimer in the placenta.

Journal of Endocrinology (1998) 159, 459-467

\section{Introduction}

As well as being of interest itself the placenta provides a unique model for understanding the process of organogenesis in the human. Vasculogenesis is evident early in placental development when cells within the fetal villi differentiate into fetal endothelial cells and are organised into functional vessels. Angiogenesis, the sprouting of new capillaries from existing vessels, is also an essential component of placental development (Demir et al. 1989). Within the villi of the placenta the fetal vasculature must develop in such a way as to ensure that sufficient capacity for exchange occurs between fetal and maternal circulations. The villous trophoblast, although not classified as endothelial in nature, is in contact with the maternal blood and must be capable of mediating the transfer of substances to and from the fetus. In humans vascular transformation occurs in the placental bed where extravillous trophoblast (EVT) cells within the maternal decidual tissue transform the spiral arteries into high flow, low resistance vessels which are more efficient at supplying the placenta with maternal blood (Pijinenborg 1994). A family of growth factors has now been identified which influence endothelial cells and result in changes to the architecture of blood vessels. We have sought to localise four members of this family: vascular endothelial growth factor (VEGF), placenta growth factor (PlGF), and VEGF-B and VEGF-C.

VEGF is a disulphide-linked homodimeric protein. Differential splicing results in five different forms of VEGF all with distinctive characteristics (Houck et al. 1991, Charnock-Jones et al. 1993). VEGF is a potent angiogenic agent in the chick chorioallantoic membrane, the rat cornea assay, and in rabbit bone angiogenesis (Connolly et al. 1989, Leung et al. 1989). It promotes endothelial cell proliferation (Connolly et al. 1989) and vascular permeability (Keck et al. 1989), as well as being a maintenance factor for newly formed blood vessels (Alon et al. 1995). Transgenic mice which are either heterozygous or homozygous for a null mutation of the VEGF gene have severe endothelial cell defects and fail to survive past embryonic day 12 (Carmeliet et al. 1996, Ferrara et al. 1996). VEGF is therefore essential for embryonic development and other members of the VEGF family are unable to compensate for even its partial loss. The actions of VEGF are mediated through the KDR (kinase domain receptor) and FLT-1 (fms-like tyrosine kinase) receptors (Shibuya et al. 1990, Terman et al. 1992). Null mutation of either of these receptors in the mouse results in embryonic death (Fong et al. 1995, Shalaby et al. 1995).

$\mathrm{PlGF}$ is a dimeric secreted factor which shares close amino acid homology to VEGF. This similarity to VEGF 
is also functionally evident in its ability to promote endothelial cell proliferation in vitro (Maglione et al. 1991). Three alternatively spliced variants have been identified with PlGF-2 having affinity for heparin (Cao et al. 1997). Recombinant PlGF-1 from eukaryotic overexpressing cells is highly active on endothelial cells in chemotactic, mitogenic and angiogenic assays (Ziche et al. 1997). Human umbilical vein endothelial cells display two classes of binding sites for PlGF homodimers. The high affinity binding is to FLT-1, while the lower affinity receptor is yet to be identified (Clauss et al. 1996). PlGF/VEGF heterodimers have been found which also bind to the KDR receptor (Cao et al. 1996). PlGF and VEGF thus appear capable of acting in unison on both monocytes and endothelial cells (Clauss et al. 1996).

VEGF-B was originally isolated from a mouse embryonic cDNA library. It has $\sim 45 \%$ amino acid homology to VEGF and a mitogenic effect on endothelial cells (Olofsson et al. 1996b). Its expression is most marked in muscle, particularly skeletal and myocardial, although Northern blotting has suggested mRNA for the two VEGF-B isoforms can be detected in the placenta (Olofsson et al. 1996a,b). VEGF-C binds the FLT-4 receptor and thus is likely to act on the lymphatics and has also been found to affect the migration and proliferation of endothelial cells (Joukov et al. 1996, Lee et al. 1996). VEGF-D has now been identified, but by Northern blotting mRNA encoding this protein was not detected in placental tissue (Yamada et al. 1997).

Angiogenesis has been shown to be an essential component of normal development with the correct balance of antagonists and inducers being crucial (Hanahan \& Folkman 1996). Within the female reproductive system blood vessel development is essential to the normal physiological processes of endometrial turnover, ovarian folliculogenesis, corpus luteum development and placentation. It has also been implicated in pathological conditions such as tumour metastasis (Fidler \& Ellis 1994). The VEGF family is a crucial regulator of angiogenesis as evidenced by the fact that a neutralising VEGF antibody can suppress tumour growth and that the soluble FLT-1 receptor can inhibit retinal neovascularisation (Kim et al. 1993, Aiello et al. 1995). In the placenta, maldevelopment of the fetal vessels within the placental villi has been associated with intra-uterine growth retardation (IUGR) and pre-eclampsia, both of which are serious problems of pregnancy (Benirschke \& Kaufmann 1995). We show here that VEGF and PlGF are produced by the placenta and that their localisation is compatible with binding to fetal endothelial cells within the villi.

\section{Materials and Methods}

\section{Tissue collection and processing for in situ hybridisation}

The study was conducted in accordance with the approval given by the ethical committee of the Addenbrookes'
Hospital NHS Trust. Gestational dates of human placentae used in this study were calculated from the 1st day of the last menstrual period and were within \pm 7 days of an ultrasound scan performed in the first trimester of pregnancy. First and third trimester material was obtained from normal placentae ( $n=5$ and 4 respectively). Placentae used for second trimester analysis $(n=5)$ were from fetuses with anencephaly. All procedures were conducted on tissue sections from formalin fixed, paraffin embedded, tissue blocks. Sections $(4 \mu \mathrm{m})$ were cut onto slides coated with 3-aminopropyltriethoxy-silane (Sigma Chemical Co., Poole, Dorset, UK) and sections from each placental sample were analysed in at least three separate hybridisation experiments. Immunohistochemical and in situ hybridisation procedures were conducted on serial sections from the same placenta.

\section{Immunohistochemistry}

To identify trophoblast cells and monocytes and macrophages immunohistochemical staining was carried out as described by Clark et al. (1996b). The antibodies used were anti-cytokeratin (clone MNF116, Dako Ltd, High Wycombe, Bucks, UK), anti-human CD68 (clone PGM1, Dako Ltd) and anti-human CD45 (Dako Ltd).

\section{In situ hybridisation}

The probes were generated from PCR products amplified from cDNA obtained from term placenta and were cloned into the pCR-Script $\mathrm{SK}(+)$ (Stratagene, Cambridge, Cambs, UK). The orientation and identity of the clones was confirmed using an ABI 373A fluorescent sequencer (Foster City, CA, USA). Riboprobes were labelled with $\left[{ }^{33} \mathrm{P}\right] \mathrm{UTP}$ and in situ hybridisation performed as previously described in detail by Clark et al. $(1996 a, b)$.

\section{VEGF probe}

The VEGF probe was a subcloned fragment of a full length human VEGF cDNA. It comprised exons 1-4 and thus would detect all the known alternatively spliced variants of VEGF. It spanned the region described by Tischer et al. (1991) from the $5^{\prime}$ ATGAAC (amino acid number - 26) to TGTGAATGC 3' (amino acid number 104). This generated a $390 \mathrm{bp}$ probe cloned into the pBluescript II KS vector (Stratagene).

\section{PlGF probe}

Primers for the amplification of PlGF were 5' GARA ARATGCCNGTNATG $3^{\prime}$ (where $\mathrm{R}=\mathrm{AG}$ and $\mathrm{N}=$ AGCT) beginning at bp 316 as described by Maglione et al. (1991) and ending with 5' CTCCAAGGGGTG 
GGTTA 3'. This generated a $533 \mathrm{bp}$ probe which contained the 63 bp insert between bases 744 and 745 as previously described by Maglione et al. (1993).

\section{VEGF-B probe}

Primers to VEGF-B were 5' TGTCTCCCAGCCTG ATGC $3^{\prime}$ beginning at bp 69 and $5^{\prime}$ TGGCTTCACAG CACTGTC $3^{\prime}$ ending at bp 408 of the EMBL sequence (accession number U48801). The resulting cDNA fragment was $340 \mathrm{bp}$ in length.

\section{VEGF-C probe}

Primers for a $183 \mathrm{bp}$ probe for VEGF-C were 5' TGTA CAAGTGTCAGCTAAGG 3' beginning at bp 590 and ending with $5^{\prime}$ CCACATCTATACACACCTCC $3^{\prime}$ at bp 772 according to Joukov et al. (1996) (EMBL accession number X94216).

\section{Reverse transcription PCR (RT-PCR) for PlGF splice variants}

Total RNA was extracted using the method of Chomczynski \& Sacchi (1987), from snap-frozen first trimester villus and term placenta. Term placenta was collected so as to have tissue from the placental/decidual interface, which by histology contains large numbers of EVT, and tissue from deep within the placenta containing only villi. cDNA was synthesised with super reverse transcriptase (HT Biotechnology Ltd, Cambridge, Cambs, $\mathrm{UK}$ ), and primed with random hexamers (Pharmacia Biotech Ltd, St Albans, Herts, UK). Primers specific for PlGF are given above and the product was amplified using a Hybaid thermal cycler for $1 \mathrm{~min}$ at $95^{\circ} \mathrm{C}$ then 35 cycles (30 s at $95{ }^{\circ} \mathrm{C}, 30 \mathrm{~s}$ at $52{ }^{\circ} \mathrm{C}, 30 \mathrm{~s}$ at $72{ }^{\circ} \mathrm{C}$ ) and a final extension for $3 \mathrm{~min}$ at $72^{\circ} \mathrm{C}$ (Hybaid, Teddington, UK).

\section{Northern blot analysis}

In order to confirm the specificity of the VEGF-C probe, Northern blotting was conducted. The integrity and relative amount of RNA loaded was assessed using a 100 bp probe for glyceraldehyde-3-phosphate dehydrogenase (GAPDH). RNA was subjected to electrophoresis and then capillary transferred onto Hybond N (Amersham International, Amersham, Bucks, UK). Probes were labelled by QuickPrime random priming (Pharmacia) with $\left[\alpha^{32} \mathrm{P}\right] \mathrm{dCTP}$. The probes were purified with a Nick Column (Pharmacia) and subsequent ethanol precipitation in the presence of yeast tRNA. Hybridisation was conducted at $65{ }^{\circ} \mathrm{C}$ in $20 \mathrm{mM}$ Tris, $0 \cdot 1 \% \mathrm{w} / \mathrm{v}$ SDS, $2 \mathrm{mM}$ tetrasodium pyrophosphate, $10 \mathrm{mM}$ polyethylene glycol, $1 \mathrm{M} \mathrm{NaCl}$ and $0.1 \mathrm{mg} / \mathrm{ml}$ sheared salmon sperm. The blot was washed in $2 \times \mathrm{SSC}$ with $0 \cdot 1 \% \mathrm{w} / \mathrm{v}$ SDS at $65{ }^{\circ} \mathrm{C}$ and autoradiography performed for $3-5$ days with two intensifying screens.

\section{Results}

First trimester placental tissue sections, from weeks 6 to 12 of gestation $(n=5)$, were probed by in situ hybridisation for PlGF and VEGF mRNA (Fig. 1). Hybridisation for mRNA encoding PlGF was strongest over the syncytiotrophoblast layer of the villus with some grains evident over the cytotrophoblast. Considerable variability existed as to where PlGF was detected both within sections and even around individual villi at this stage of gestation, with clusters of villi having no hybridisation signal at all. However, areas where there were columns attaching to the decidua were always strongly labelled. No hybridisation for VEGF mRNA was detected in association with the villous trophoblast. Positive cells were, however, clustered within some villi. There were more villi with positive cells at this stage of gestation than compared with term placenta. The villi containing positive cells tended to be larger with more fibroblast-like cells. Serial or near serial sections were immunostained for CD68 to identify Hofbauer cells. The VEGF-positive cells did not share the same distribution as the Hofbauer cells. Sense control probes for both VEGF and PlGF gave levels of background label similar to that shown in Fig. 1B.

In the first trimester of pregnancy, PlGF mRNA was found to be produced by the EVT cells within the maternal decidual (Fig. 2). This pattern continued throughout pregnancy. A strong signal was detected for VEGF mRNA in the maternal glandular cells (not shown), as well as within a population of large cells associated with areas of necrosis. The location, morphology and immunostaining pattern for CD45 and CD68 on sections nearby indicated that these cells were macrophages.

From weeks 14 to 22 of pregnancy $(n=5)$ no PlGF mRNA was detected within the villous trophoblast while the EVT cells in the same sections continued to be positive. VEGF mRNA continued to be detected within the stroma of the occasional large villous.

At the end of gestation the trophoblast layers were highly positive for the PlGF probe (Fig. 3, $n=4$ ). RNA encoding VEGF was found within only a few villi at term. These cells were not CD68 positive and thus not Hofbauer cells. A summary of the findings is presented in Table 1.

In situ hybridisation revealed that the amniotic mesoderm but not amniotic epithelium was strongly positive for mRNA encoding VEGF as were some cells within the chorionic plate (data not shown).

No VEGF-B or VEGF-C mRNA was detected by in situ hybridisation in the placenta at any stage of gestation 

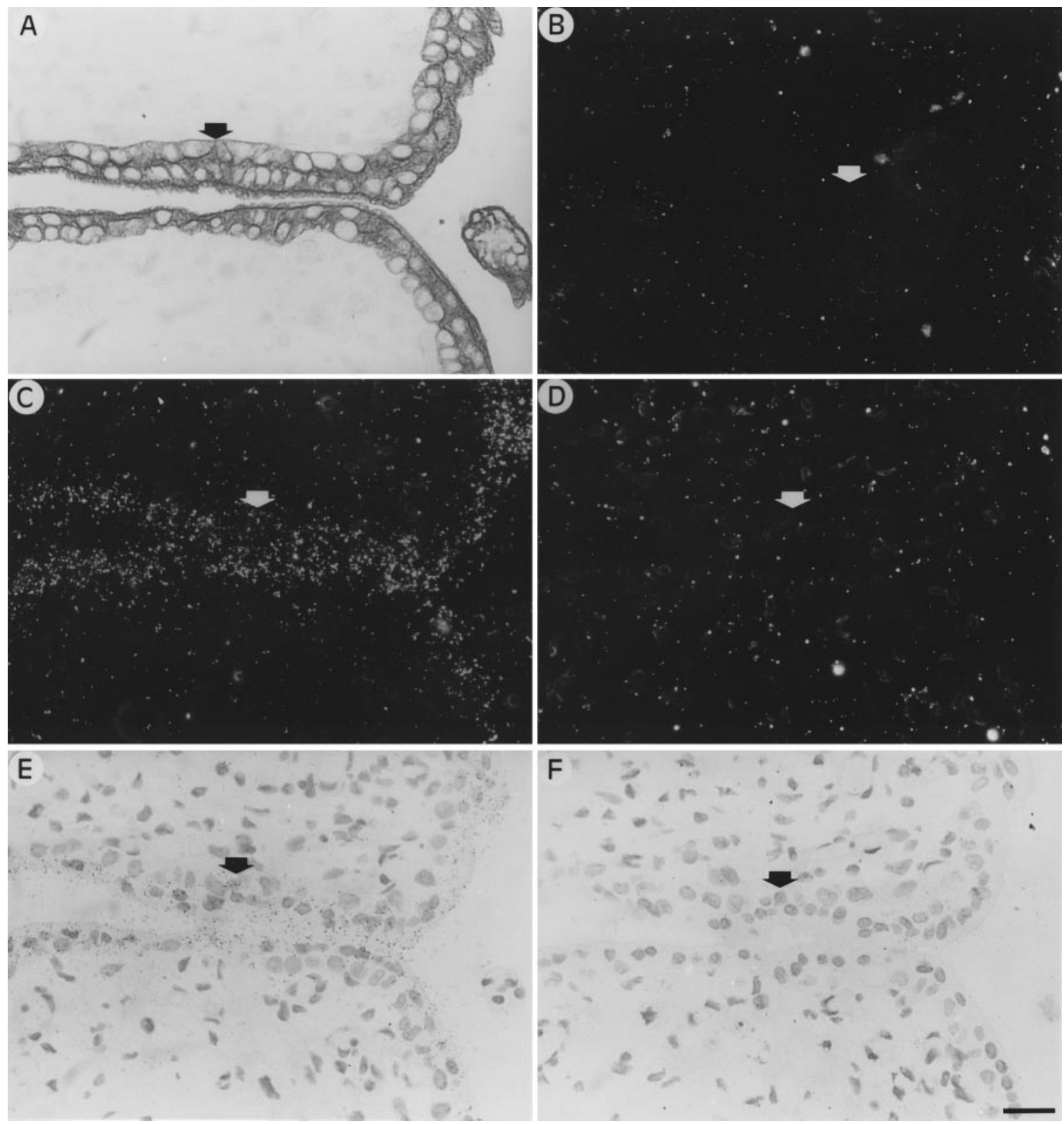

Figure 1 Serial sections of villi in week 12 of gestation. Arrow indicates the cytotrophoblast and outer syncytiotrophoblast layers. Cytokeratin immunostaining identified the villous trophoblast (A). In situ hybridisation for mRNA encoding PIGF with the sense probe (B) and anti-sense probe (C). In situ hybridisation for VEGF with no positive hybridisation in the trophoblast (D). Brightfield photograph of PIGF hybridisation reveals the presence of positive trophoblast and negative stromal cells (E). (F) Brightfield of the VEGF in situ hybridisation. Scale bar equates to $25 \mu \mathrm{m}$.

(Fig. 4). However, we have localised cells containing mRNA encoding VEGF-B in ovarian tumours (Sowter et al. 1997) and similar specimens were analysed in parallel with the placental samples. These consistently showed strong positive hybridisation signals, whereas in the placental samples the signal remained not detected. These same placental samples hybridised with the VEGF and PlGF probes described elsewhere in this manuscript. The
VEGF-C probe was tested by Northern blotting. A single band of the predicted size was detected in total RNA from human adrenal gland and in the placenta but only after a 5-day exposure (Fig. 5). There was variable amount of the VEGF-C present as demonstrated by the difference between the samples in lanes 2 and 3 of Fig. 5 .

RT-PCR in the placenta indicated the presence of alternative splicing for PlGF ( $n=4$ in each group). PlGF-2, 


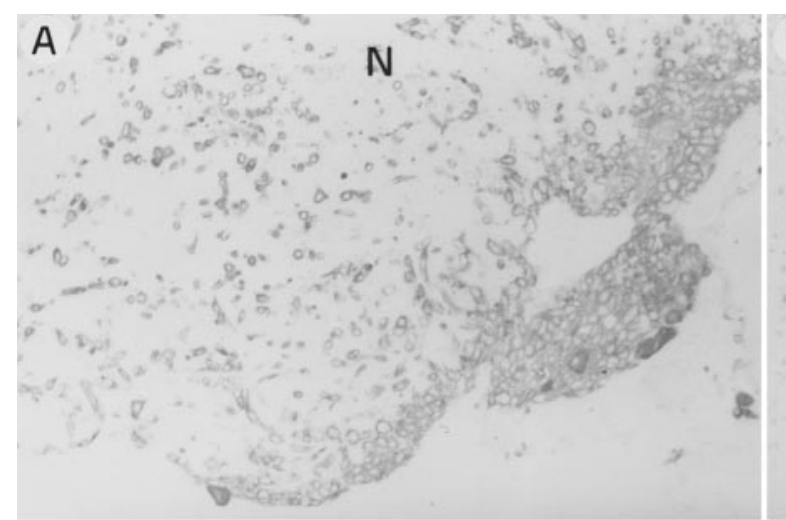

B
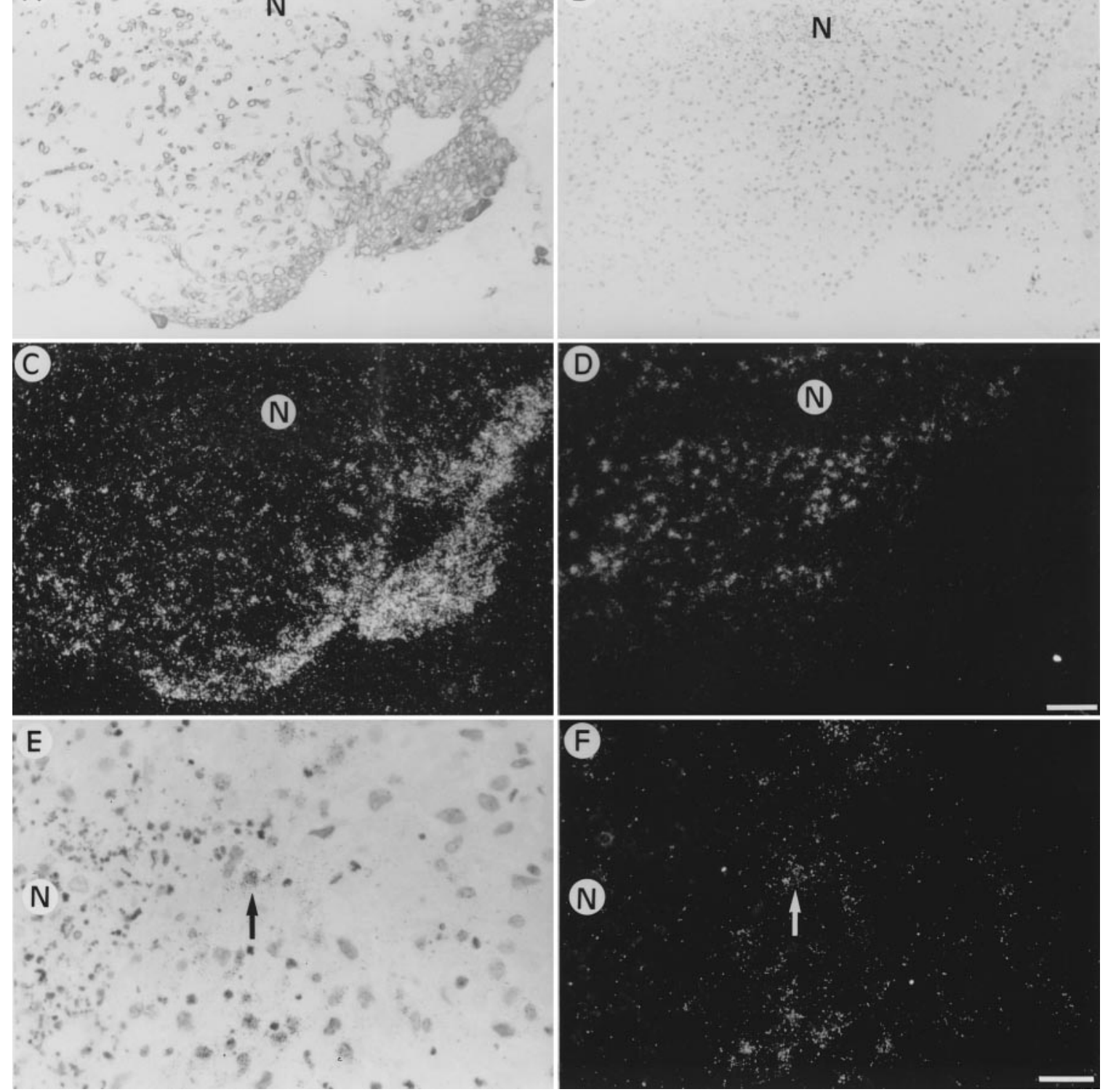

Figure 2 Serial sections of first trimester decidual tissue (week 6). The necrotic area known as Nitabuch's layer is labelled N. Immunostaining for cytokeratin to identify the EVT cells (A). Brightfield image of the tissue (B). In situ hybridisation for PIGF mRNA (C) and VEGF mRNA (D). Higher magnification of VEGF-positive cells on the edge of the necrotic area (arrows); brightfield (E) and darkfield (F). Scale bar in (D) equates to $100 \mu \mathrm{m}$ for panels A-D. For panels $E$ and $F$ scale bar in (F) equates to $25 \mu \mathrm{m}$.

which has a $63 \mathrm{bp}$ insert (530 bp), was consistently found as a stronger band than PlGF-1 (470 bp). A third band at $680 \mathrm{bp}$ was cloned and was not related to PlGF.

\section{Discussion}

Regulation of angiogenesis within the placenta is critical for the development of a healthy placenta and thus a healthy fetus. The in situ hybridisation results presented here indicate that the angiogenic agents VEGF and PlGF are found within the placenta but that they are produced by different cell types and thus are unlikely to form heterodimers. We have previously reported that when using a full length VEGF probe in situ hybridisation studies showed that the villous trophoblast cells contained mRNA encoding VEGF (Sharkey et al. 1993). This is in contrast to the data contained in this manuscript. The in situ 


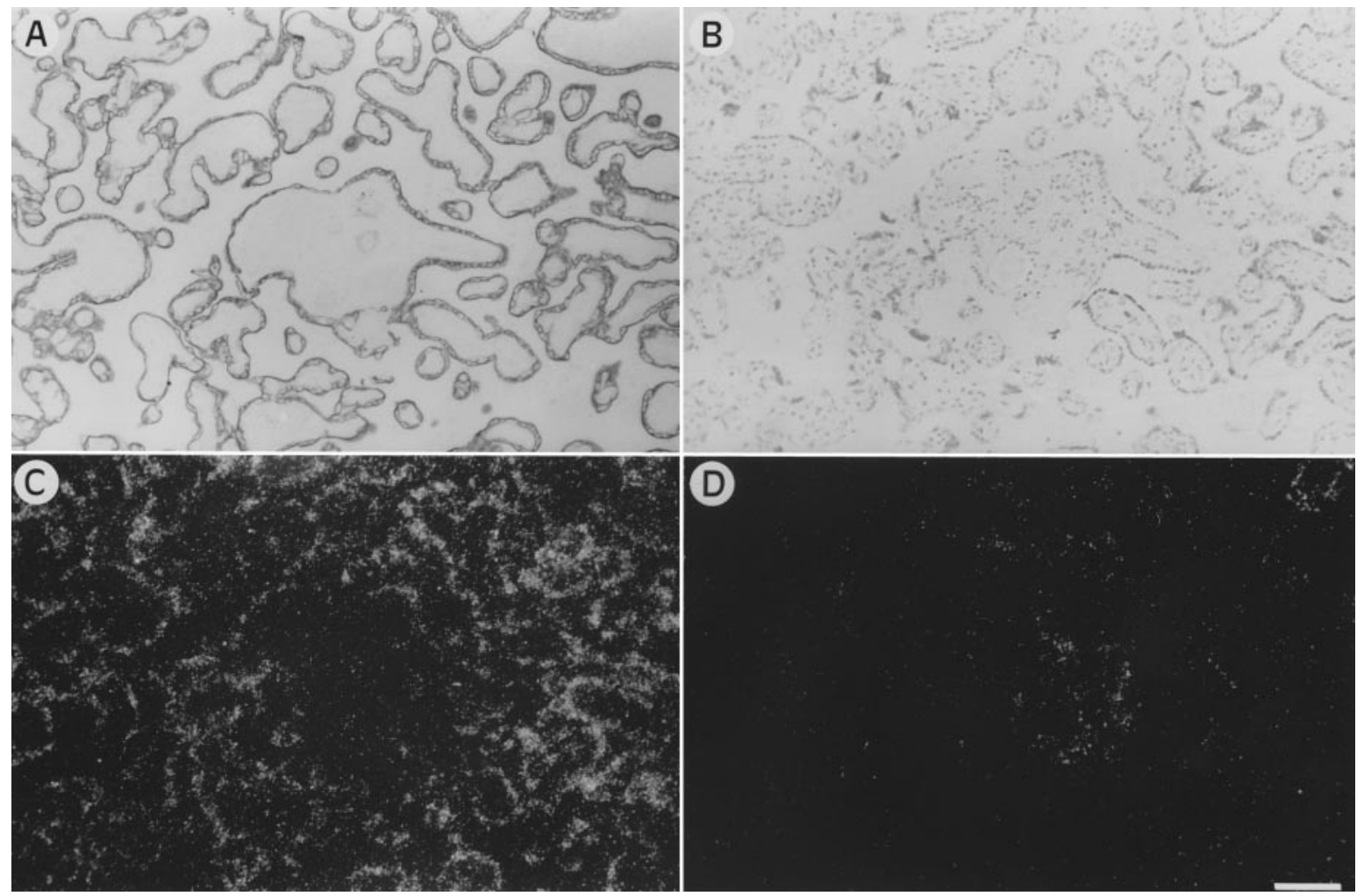

Figure 3 Serial sections of term placenta immunostained for cytokeratin to identify the trophoblast (A). A brightfield photograph (B). PIGF mRNA within the villous trophoblast (C) and VEGF mRNA detected in cells within the villi (D). Scale bar equates to $100 \mu \mathrm{m}$ for all panels.

hybridisation studies described here were performed with a probe directed against exons $1-4$ of VEGF. This is a region with low homology to other members of the VEGF family and we were unable to detect mRNA encoding VEGF within the trophoblast. It appears likely that the full length probe used in the previous studies cross-reacted with PlGF in the trophoblast layers. This would be consistent with the findings of Vuorela et al. (1997), who did not detect any mRNA encoding VEGF associated with the villi of the term placenta. In this paper we also report that in situ hybridisation for VEGF mRNA detected some positive cells within the villi. These cells were not Hofbauer cells and tended to be located within only a few intermediate or stem villi in each section. There were thus only a small number of positive cells within the placenta.

Previous research has found that the levels of VEGF within maternal serum increase during pregnancy (Anthony et al. 1997) but that measuring these levels is complicated by the presence of VEGF-binding proteins. We show here that the source of circulating VEGF is unlikely to be the placental villi. However, the decidual glands and macrophages produce large amounts of VEGF, some of which could potentially contribute to the levels in the maternal circulation. It is also possible that other sources such as the ovary (Kamat et al. 1995) and breast (Brown et al. 1995) contribute to circulating VEGF.

Table 1 Summary of PIGF and VEGF in situ hybridisation results

\begin{tabular}{|c|c|c|c|c|}
\hline & \multicolumn{3}{|l|}{ PIGF } & \multirow{2}{*}{$\begin{array}{l}\text { VEGF } \\
\text { (week } 6 \text { to term) }\end{array}$} \\
\hline & Week 6-12 & Week 14-22 & Term & \\
\hline Villous trophoblast & ++ & - & $\overline{+++}$ & - \\
\hline Villous stroma & - & - & - & + \\
\hline EVT cells & +++ & +++ & +++ & - \\
\hline Maternal glands & - & - & - & +++ \\
\hline Non-EVT maternal cell & - & - & - & +++ \\
\hline
\end{tabular}



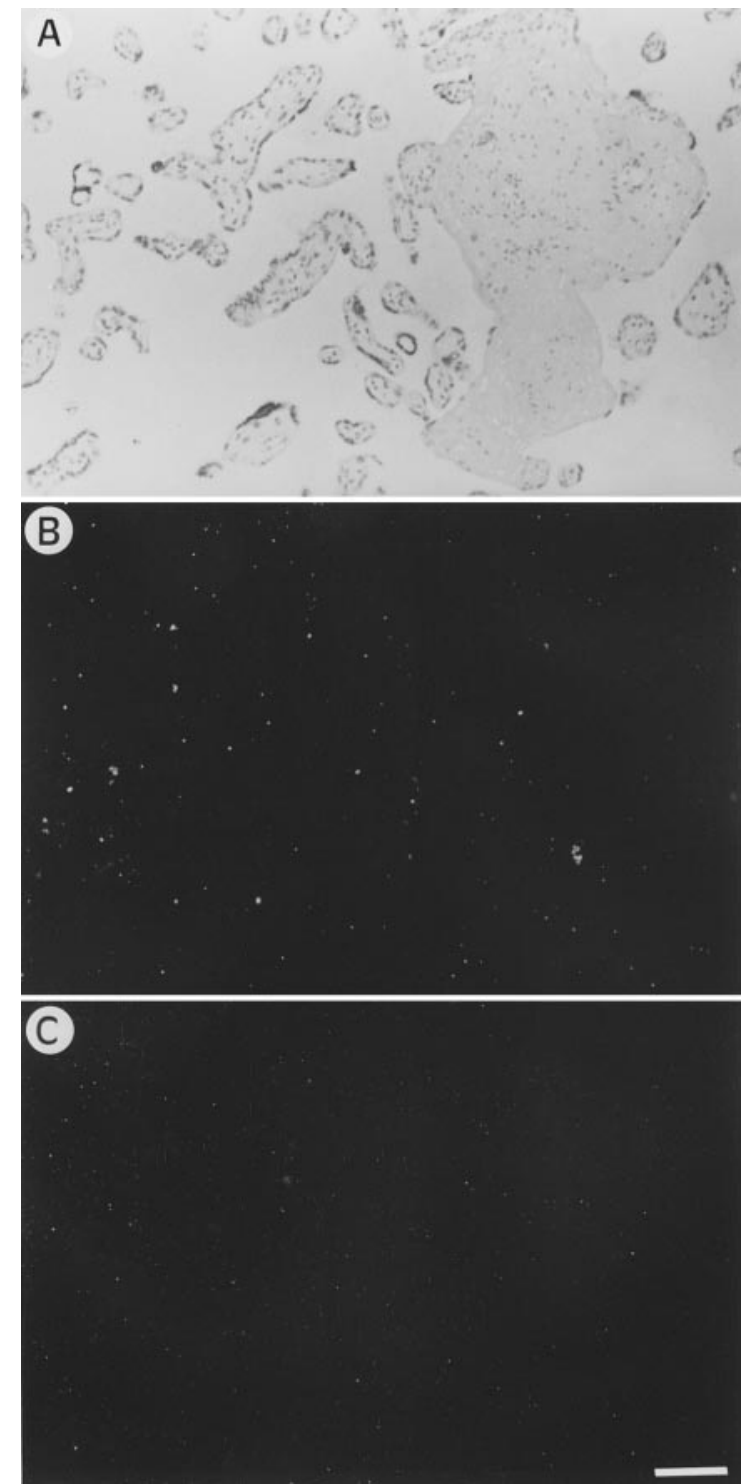

Figure 4 Brightfield (A) of term placenta and in situ hybridisation on serial sections for VEGF-B (B) and VEGF-C (C). Scale bar equates to $100 \mu \mathrm{m}$ for all panels.

The mRNA encoding PlGF was localised in the villous trophoblast layers and the levels were regulated throughout pregnancy. The term placenta, which is large in size and thus has a large surface area of trophoblast, contained a consistently strong signal for PlGF mRNA. Khaliq et al. (1996) and Vuorela et al. (1997) also found PlGF mRNA in the term villus but did not investigate other stages of pregnancy. The abundant PlGF mRNA is likely to lead to significant quantities of PlGF protein being produced, and this is confirmed by the fact that immunoreactive PlGF can readily be detected in maternal circulation during pregnancy (data not shown).

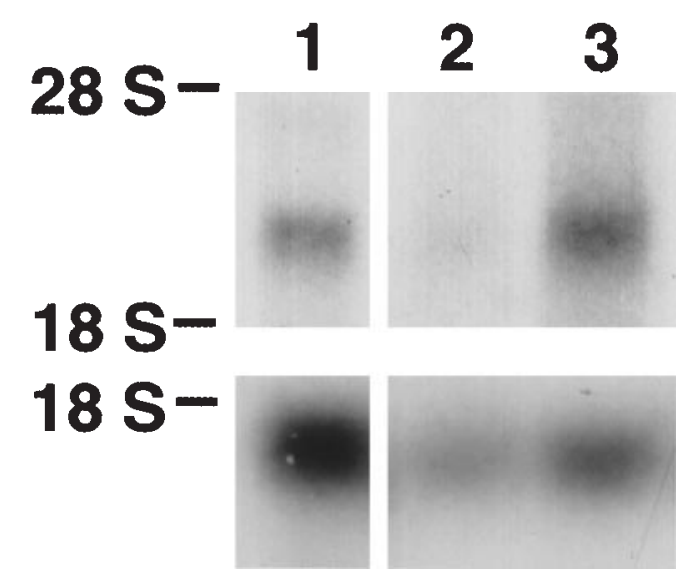

Figure 5 Northern blotting for VEGF-C detected only one positive band, which was between the 28S and 18S ribosomal RNA bands. RNA from human adrenal gland (lane 1) and term placentae (lanes 2 and 3 ) were positive. The blot was re-probed for GAPDH as a control and this was evident below the $18 \mathrm{~S}$ band (lanes 1-3).

Although Northern blots for VEGF-B (Olofsson et al. 1996a,b) and VEGF-C (Joukov et al. 1996, Lee et al. 1996) suggest the presence of mRNA in the placenta we were unable to detect this by in situ hybridisation. Vuorela et al. (1997) have also investigated the presence of VEGF, VEGF-B and VEGF-C mRNA by Northern blotting. However, the mixing of the probes into a pool makes it difficult to assess accurately which mRNAs are present, especially when multiple splice variants exist for at least VEGF and VEGF-B (Olofsson et al. 1996a). Furthermore in all of these studies only a single lane of a multiple tissue Northern blot (Clontech, Palo Alto, CA, USA) was used. It is possible that in situ hybridisation is not sensitive enough to detect any message which might be present in the placenta. Thus it would seem likely that VEGF and PlGF are the most important members of the family in the placenta.

The correct development and branching of the fetal capillaries is important in ensuring efficient transport to and from the fetus. Diseases such as IUGR and preeclampsia are characterised by abnormalities of the fetal endothelial cells within the villi. We have previously shown by ligand binding with ${ }^{125} \mathrm{I}-\mathrm{VEGF}$ that the major site of action for VEGF is the endothelial cells within the fetal villi which have both the FLT-1 and KDR receptors. ${ }^{125} \mathrm{I}$-VEGF was not found to bind to the trophoblast, which produces large amounts of soluble FLT-1 (Clark et al. 1998). The in situ hybridisation conducted for VEGF indicated that a relatively small number of isolated cells within the villous core and cells within the decidua contain mRNA encoding VEGF. We have identified throughout gestation the cells in the placenta which contain the mRNA encoding PlGF. This protein has previously been detected by Western blotting in placental 
homogenates and we have evidence that it is readily detectable in the maternal circulation (data not shown). PlGF is produced in large amounts by the placental villi, binds the FLT-1 receptor with high affinity and may potentiate the actions of low concentrations of VEGF. PlGF has also recently been found to act as an angiogenic agent independently of VEGF (Ziche et al. 1997). PlGF is therefore likely to be important as a local mediator of angiogenesis within the placental villi. We do not as yet know if the soluble FLT-1 produced by the trophoblast can bind and antagonise endogenous PlGF, but it seems likely that it would, and this would alter the bioavailability of PlGF.

We have shown that the mRNAs encoding the angiogenic factors VEGF and PlGF are present within the decidua and the placental villi but that there is no co-localisation of these messages. mRNA encoding PlGF is readily detectable within the placental trophoblast. PlGF protein could potentially act both within the placental villi as well as systemically within the maternal circulation. The ability of these ligands to bind to the FLT-1 receptor makes them strong candidates for controlling angiogenesis within the placenta villi.

\section{Acknowledgements}

D E C was supported by a UK Medical Research Council project grant: G9331232PA.

\section{References}

Aiello LP, Pierce EA, Foley ED, Takagi H, Chen H, Riddle L, Ferrara N, King GL \& Smith LEH 1995 Suppression of retinal neovascularization in vivo by inhibition of vascular endothelial growth factor (VEGF) using soluble VEGF-receptor chimeric proteins. Proceedings of the National Academy of Sciences of the USA 92 10457-10461.

Alon T, Hemo I, Itin A, Pe'er J, Stone J \& Keshet E 1995 Vascular endothelial growth factor acts as a survival factor for newly formed retinal vessels and has implications for retinopathy of prematurity. Nature Medicine 1 1024-1028.

Anthony FW, Evans PW, Wheeler T \& Wood PJ 1997 Variation in detection of VEGF in maternal serum by immunoassay and the possible influence of binding proteins. Annals of Clinical Biochemistry 34 276-280.

Benirschke K \& Kaufmann P 1995 Pathology of the Human Placenta. London: Springer-Verlag.

Brown LF, Berse B, Jackman RW, Tognazzi K, Guidi AJ, Dvorak HF, Senger DR, Connolly JL \& Schnitt SJ 1995 Expression of vascular permeability factor (vascular endothelial growth factor) and its receptors in breast cancer. Human Pathology 26 86-91.

Cao Y, Chen H, Zhou L, Chiang M-K, Anand-Apte B, Wetherbee JA, Wang Y, Fang F, Flanagan JG \& Tsang ML-S 1996 Heterodimers of placenta growth factor/vascular endothelial growth factor. Journal of Biological Chemistry 271 3154-3162.

Cao Y, Ji WR, Qi P, Rosin A \& Cao Y 1997 Placenta growth factor: identification and characterization of a novel isoform generated by RNA alternative splicing. Biochemical and Biophysical Research Communications 235 493-498.
Carmeliet P, Ferreira V, Breier G, Pollefeyt S, Kieckens L, Gertsenstein M, Fahrig M, Vandenhoeck A, Harpal K, Eberhardt C, Declercq C, Pawling J, Moons L, Collen D, Risau W \& Nagy A 1996 Abnormal blood vessel development and lethality in embryos lacking a single VEGF allele. Nature 380 435-439.

Charnock-Jones DS, Sharkey AM, Rajput-Williams J, Burch D, Schofield JP, Fountain SA, Boocook CA \& Smith SK 1993 Identification and localization of alternately spliced mRNAs for vascular endothelial growth factor in human uterus and estrogen regulation in endometrial carcinoma cell lines. Biology of Reproduction 48 1120-1128.

Chomczynski P \& Sacchi N 1987 Single step method of RNA isolation by acid guanidinium thiocyanate-phenol-chloroform extraction. Analytical Biochemistry 162 156-159.

Clark DE, Smith SK, Sharkey AM \& Charnock-Jones DS 1996a Localization of VEGF and expression of its receptors flt and KDR in human placenta throughout pregnancy. Human Reproduction 11 1090-1098.

Clark DE, Smith SK, Sharkey AM, Sowter HM \& Charnock-Jones DS 1996b. Hepatocyte growth factor/scatter factor and its receptor c-met: localization and expression in the human placenta throughout pregnancy. Journal of Endocrinology 151 459-467.

Clark DE, Smith SK, He Y, Day K, License DR \& Charnock-Jones DS 1998 A vascular endothelial growth factor antagonist is produced by the placenta and released into the maternal circulation. Biology of Reproduction (In Press).

Clauss M, Weich H, Breier G, Knies U, Rockl W, Waltenberger J \& Risau W 1996 The vascular endothelial growth factor receptor Flt-1 mediates biological activity. Journal of Biological Chemistry 271 17629-17634.

Connolly DT, Heuvelman DM, Nelson R, Olander JV, Eppley BL, Delfino JJ, Siegel NR, Leimgruber RM \& Feder J 1989 Tumour vascular permeability factor stimulates endothelial cell growth and angiogenesis. Journal of Clinical Investigation 84 1470-1478.

Demir R, Kaufmann P, Castellucci M, Erbengi T \& Kotowshi A 1989 Fetal vasculogenesis and angiogenesis in human placental villi. Acta Anatomica 136 190-203.

Ferrara N, Carver-Moore K, Chen H, Dowd M, Lu L, O'Shea SK, Powell-Braxton L, Hillan KJ \& Moore MW 1996 Heterozygous embryonic lethality induced by targeted inactivation of the VEGF gene. Nature 380 439-442.

Fidler IJ \& Ellis LM 1994 The implications of angiogenesis for the biology and therapy of cancer metastasis. Cell 79 185-188.

Fong G-H, Rossant J, Gertsenstein M \& Breitman ML 1995 Role of the Flt-1 receptor tyrosine kinase in regulating the assembly of vascular endothelium. Nature 376 66-70.

Hanahan D \& Folkman J 1996 Patterns and emerging mechanisms of the angiogenic switch during tumorigenesis. Cell 86 353-364.

Houck KA, Ferrara N, Winer J, Cachianes G, Li B \& Leung DW 1991 The vascular endothelial growth factor family: identification of a fourth molecular species and characterisation of alternative splicing of RNA. Molecular Endocrinology 5 1806-1814.

Joukov V, Pajusola K, Kaipainen A, Chilov D, Lahtinen I, Kukk E, Saksela O, Kalkkinen N \& Alitalo K 1996 A novel vascular endothelial growth factor, VEGF-C, is a ligand for the Flt4 (VEGFR-3) and KDR (VEGFR-2) receptor tyrosine kinases. EMBO Journal 15 290-298.

Kamat BR, Brown LF, Manseau EJ, Senger DR \& Dvorak HF 1995 Expression of vascular permeability factor/vascular endothelial growth factor by human granulosa and theca lutein cells. Role in corpus luteum development. American Journal of Pathology 146 $157-165$.

Keck PJ, Hauser SD, Krivi G, Sanzo K, Warren T, Feder J \& Connolly DT 1989 Vascular permeability factor, an endothelial cell mitogen related to PDGF. Science 246 1309-1312.

Khaliq A, Li XF, Shams M, Sisi P, Acevedo CA, Whittle MJ, Weich H \& Ahmed A 1996 Localisation of placenta growth factor (PlGF) in human term placenta. Growth Factors 13 243-250. 
Kim KJ, Li B, Winer J, Armanini M, Gillett N, Phillips HS \& Ferrara N 1993 Inhibition of vascular endothelial growth factor-induced angiogenesis suppresses tumour growth in vivo. Nature 362 841-844.

Lee J, Gray A, Yuan J, Luoh S-M, Avraham H \& Wood WI 1996 Vascular endothelial growth factor-related protein: a ligand and specific activator of the tyrosine kinase receptor Flt4. Proceedings of the National Academy of Sciences of the USA 93 1988-1992.

Leung DW, Cachianes G, Kuang W-J, Goeddell DV \& Ferrara N 1989 Vascular endothelial growth factor is a secreted angiogenic mitogen. Science 246 1306-1309.

Maglione D, Guerriero G, Viglietto G, Delli-Bovi P \& Persico MG 1991 Isolation of a human placenta cDNA coding for a protein related to the vascular permeability factor. Proceedings of the National Academy of Sciences of the USA 88 9267-9271.

Maglione D, Guerriero G, Viglietto G, Ferraro MG, Aprelikova O, Alitalo K, Vecchio SD, Lei K-J, Chou JY \& Persico MG 1993 Two alternative mRNAs coding for the angiogenic factor, placenta growth factor (PlGF), are transcribed from a single gene of chromosome 14. Oncogene 8 925-931.

Olofsson B, Pajusola K, Euler GV, Chilov D, Alitalo K \& Eriksson U $1996 a$ Genomic organization of the mouse and human genes for vascular endothelial growth factor B (VEGF-B) and characterization of a second splice isoform. Journal of Biological Chemistry 271 19310-19317.

Olofsson B, Pajusola K, Kaipainen A, Euler GV, Joukov V, Saksela O, Orpana A, Pettersson RF, Alitalo K \& Eriksson U 1996b Vascular endothelial growth factor B, a novel growth factor for endothelial cells. Proceedings of the National Academy of Sciences of the USA 93 2576-2581.

Pijinenborg R 1994 Trophoblast invasion. Reproductive Medicine Review 3 53-73.

Shalaby F, Rossant J, Yamaguchi TP, Gertsenstein M, Wu X-F, Breitman ML \& Schuh AC 1995 Failure of blood-island formation and vasculogenesis in Flk-1-deficient mice. Nature 376 62-66.

Sharkey AM, Charnock-Jones DS, Boocock CA, Brown KD \& Smith SK 1993 Expression of mRNA for vascular endothelial growth factor in human placenta. Journal of Reproduction and Fertility 99 609-615.

Shibuya M, Yamaguchi S, Yamane A, Ikeda T, Tojo A, Matsushime H \& Sato M 1990 Nucleotide sequence and expression of a novel human receptor-type tyrosine kinase gene (ft) closely related to the fms family. Oncogene 5 519-524.

Sowter HM, Corps AN, Evans AL, Clark DE, Charnock-Jones DS \& Smith SK 1997 Expression and localisation of the vascular endothelial growth factor family in ovarian epithelial tumours. Laboratory Investigation 77 607-614.

Terman BI, Dougher-Vermazen M \& Carrion ME 1992 Identification of the KDR tyrosine kinase as a receptor for vascular endothelial cell growth factor. Biochemical and Biophysical Research Communications 187 1579-1586.

Tischer E, Mitchell R, Hartman T, Silva M, Gospodarowicz D, Fiddes JC \& Abraham JA 1991 The human gene for vascular endothelial growth factor. Journal of Biological Chemistry 266 11947-11954.

Vuorela P, Hatva E, Lymboussaki A, Kaipainen A, Joukov V, Persico MG, Alitalo K \& Halmesmaki E 1997 Expression of vascular endothelial growth factor and placenta growth factor in human placenta. Biology of Reproduction 56 489-494.

Yamada Y, Nezu J-I, Shimane M \& Hirata Y 1997 Molecular cloning of a novel vascular endothelial growth factor, VEGF-D. Genomics 42 483-488.

Ziche M, Maglione D, Ribatti D, Morbidelli L, Lago CT, Battisti M, Paoletti I, Barra A, Tucci M, Parise G, Vincenti V, Granger HJ, Viglietto G \& Persico MG 1997 Placental growth factor-1 is chemotactic, mitogenic, and angiogenic. Laboratory Investigation $\mathbf{7 6}$ 517-531.

Received 28 January 1998

Revised manuscript received 8 June 1998

Accepted 6 August 1998 